\title{
Confronting entrenched viewpoints to overcome polarity and prompt social change in the food system
}

\author{
Review by Emily Nink * \\ Boston, Massachusetts
}
Review of No Table Too Small: Engaging in the Art and Attitude of Social Change, by Laura M. Titzer. (2017). Published by CreateSpace Independent Publishing Platform. Available as paperback and eBook; 190 pages.

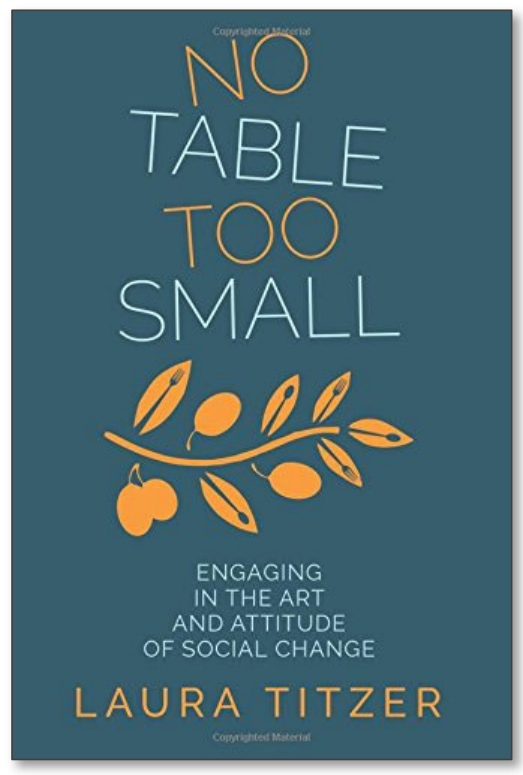

Submitted November 2, 2017 / Published online December 20, 2017

Citation: Nink, E. (2017). Confronting entrenched viewpoints to overcome polarity and prompt social change in the food system [Book review]. Journal of Agriculture, Food Systems, and Community Development. Advance online publication. http://dx.doi.org/10.5304/jafscd.2017.074.020

Copyright (C) 2017 by New Leaf Associates, Inc.

$I^{\text {n }}$ n a year defined by political turmoil and policy surprises, food justice activists are emerging from a new phase of strategic visioning for broader growth and deeper impact. The recent political shift at the federal level (and its exposure of latent, persistent cultural and political polarization) has

* Emily earned her M.S. through the Agriculture, Food and Environment program at the Tufts Friedman School of Nutrition Science and Policy, where her research and published works focused on local produce in Massachusetts farmers markets and community food security. She now works at a research center to provide technical assistance to local governments in crafting and implementing public health policies. In addition, Emily serves in a volunteer capacity as the Development Coordinator for Everett Community Growers, an urban agriculture and food justice group serving Everett, MA. Emily can be reached at emilynink@gmail.com. catapulted food systems strategizing into a new mode of thinking - thinking that probes more existential, root-cause issues. My inbox has been filled with indications of the food movement's soul searching, with such questions as: "How can we shift what's politically feasible and get at deeper root-cause issues?"; "How can we mobilize more young people than ever before into the fight for food justice and broader resistance?"; and "How can we help massively shift consciousness in urban and rural communities around issues of corporate control and white supremacy in our food system?" (H. Weinronk, Real Food Challenge, personal communication, May 23, 2017).

Laura Titzer's timely handbook, No Table Too Small: Engaging in the Art and Attitude of Social Change, 
may not have all the answers to these big questions, but it provides tools for digging deeper into critical issues, bridging divisions across sociocultural and political groups, and co-creating a vision for a broader, more inclusive food movement.

Throughout the book, which is divided into sections based on six capabilities of a successful change agent, Titzer focuses on processes that could enable social change, rather than outcomes. Writing from her extensive personal experience as a group convener and facilitator, she provides anecdotal evidence of the importance of these six capabilities. Her discussion delves into theories of change only briefly, in keeping with her own advice of breaking down an "expert-driven culture" that she believes could be detrimental to the collaborative success of the food movement.

The first capability of a change agent-holding space-involves allowing group participants to define the meeting or workshop agenda, overcoming surface-level conflicts of interest to find areas for collaboration, and engaging in a culturally competent matter. These are generally understood, and yet widely underused, practices that could benefit virtually every kind of meeting or workshop.

Components of the second capability, communication, include "deep listening," asking questions, relating to others, and practicing empathy. Rather than employing the tools of communication in the pursuit of conflict resolution, Titzer suggests that conflict management may be a more realistic goal; by using good communication to embrace points of conflict with opponents, she suggests, participants may confront their own entrenched viewpoints in an empathetic, constructive way. She also invites readers to extend the idea of conflict management to imagine collaboration between organizations that may seem "diametrically opposed” (e.g., Monsanto and La Via Campesina), proposing that facilitation could allow representatives from these organizations to discover shared values (pp. 74-76). Many passionate food activists - especially those who have committed to lengthy work on a single issue or worked directly in opposition to corporate control of the food systemmay find this message hard to swallow, yet Titzer's invitation to imagine successful collaboration between opponents may be appealing to others for its bottom-up approach and emphasis on changing individual beliefs and assumptions in order to engender organizational and institutional shifts.

"Reflection in action" dwells in what Titzer calls "points of intervention." First defining these points as uncomfortable moments in which a facilitator must adapt to the circumstances of a particular meeting on the fly, she then moves on to discuss points of intervention for behavioral changes. The reader begins to glimpse an underlying theory of social change: "change is relentless incrementalism" (p. 91). Making the case for "brave public acts," Titzer regards intervention points for behavior change as instruments for moving through a "cycle of social change to end up with new structures in place" (p. 92).

Cocreation, the fourth capability, is "the ability to involve all actors directly, and in some cases, repeatedly, from beginning to end to achieve a compelling purpose" (p. 109). Arguably, this definition is broad enough to capture the concepts of the other five capabilities; for instance, communication, reflection in action, and leadership all seem to contribute to a co-created vision for food system change. In revisiting cultural competency as a "component" of co-creation, Titzer is able to expand upon concepts introduced in the "Holding Space" section, and begins to apply the best practices introduced earlier in the book to the process of influencing public policy.

In the first four chapters, the discussion floats freely between the role of the facilitator and the roles of the participants, leaving the reader to wonder if the author considers everyone in a given group to be a change agent, or whether there is meant to be a facilitator guiding the discussion and inspiring these capabilities in others. The fifth capability, leadership, brings the focus back to the role of the organizer. Titzer sees this leader as responsible for maintaining certain co-existing conditions within the group: disequilibrium (surfacing conflict and disrupting patterns), amplification (bringing new people in and magnifying impact), and self-organization (stabilizing feedback from the amplification process).

"Systems thinking" involves identifying and recognizing the many sectors, stakeholders, 
processes, and relationships that make up the ecology of the food system. Viewed as a network, rather than a hierarchy, these many actors represent the multitude of voices referenced by the other chapters; the food system is the setting in which the practices of conflict management, communication, and collaboration are meant to take place.

Taken together, these six capabilities illustrate not only a successful change agent, but also the ideal group dynamic, extending far beyond the leadership role of a community organizer to inform all types of participants at the metaphorical table. Although the topics presented are abstract, and the writing style tends to obscure the author's meaning, the underlying lessons could certainly be applicable to the process of social change in the food system. While anyone working in that space might benefit from Titzer's reflections, those who are more seasoned might extract particular value by applying her lessons learned to their own personal experiences with group facilitation.

In the face of new political challenges, organizers working to build a broader food justice coalition are employing new strategies, including "Developing new and deeper alliances with groups working on other related issues... finding unlikely allies in the private sector... and convening both the 'usual suspects' and new constituencies to analyze and advocate for improvements to food environments and nutritional health, and mobilize constituencies before extensive harm is done" (Cohen, Poppendieck, \& Freudenberg, 2017, pp. 55-56). As these emerging strategies gain momentum, the time is ripe for organizers and change agents to reflect deeply on the individual and cultural changes needed to achieve collaborative success, and broader social change, in today's polarized sociopolitical environment.

\section{Reference}

Cohen, N., Poppendieck, J., \& Freudenberg, N. (2017). Food justice in the Trump age: Priorities for urban food advocates. CUNY Academic Works. Retrieved from http://academicworks.cuny.edu/sph pubs/161 